\title{
O CÁlCulo Diferencial e INTEGRAL E A FORMAÇÃo de ENGENHEIros
}

\author{
The Differential and Integral Calculus AND The Engineer's \\ EDUCATION
}

\begin{abstract}
Milton Luís Ribeiro Júnior
Aluno do curso de Licenciatura em Matemática da Universidade Estadual Paulista Júlio de Mesquita Filho (UNESP) Câmpus de Guaratinguetá. São Paulo. Brasil. milton.ribeiro9@gmail.com
\end{abstract}

Profa. Dra. Fabiane Mondini Doutora em Educação Matemática pela Universidade Estadual Paulista Júlio de Mesquita Filho (UNESP) - Câmpus de Rio Claro. Professora da Universidade Estadual Paulista Júlio de Mesquita Filho (UNESP) - Câmpus de Sorocaba. Sorocaba. São

Paulo. Brasil.

fabiane.mondini@unesp.br

\begin{abstract}
Profa. Dra. Luciane Ferreira Mocrosky
Doutora em Educação Matemática pela Universidade Estadual Paulista Júlio de Mesquita Filho (UNESP) - Câmpus de Rio Claro. Professora da Universidade Tecnológica Federal do Paraná (UTFPR), do PPGFCET (UTFPR) e do PPGECM (UFPR). Curitiba. Paraná. Brasil. mocrosky@utfpr.edu.br
\end{abstract}

Resumo: Neste artigo apresentaremos um estudo sobre o que os professores dizem do curso de Cálculo Diferencial Integral I para as turmas de engenharia da UNESP- Câmpus de Guaratinguetá. Trata-se de uma pesquisa qualitativa, desenvolvida na abordagem fenomenológica, que procurou responder à seguinte interrogação: “o que é isto, o Cálculo, na formação do engenheiro?”. Tratou-se de uma pesquisa abrangente, que buscou resposta para a interrogação por diversos caminhos. Nesse texto, apresentamos um estudo sobre as compreensões dos professores que ministram a disciplina no Câmpus. Destacamos a relevância da pesquisa frente às potencialidades de promover discussões sobre o ensino dessa disciplina, focando-a por seus aspectos formativos, devido a sua presença nos saberes das mais distintas áreas da ciência.

Palavras-chave: Educação Matemática. Fenomenologia. Pesquisa Qualitativa.

\begin{abstract}
In this paper we will present a study about what teachers say about the Differential and Integral Calculus course for the engineering students of São Paulo State University (UNESP), Guaratinguetá Campus. This is a qualitative research developed in the phenomenological approach, which seeks to answer the following question: What is it, the Calculus, in the formation of the Engineer? " It was a wide survey, that tried to answer this question by several ways. In this text we present a study about the understandings of the teachers that teach the discipline in the Campus. We highlight the relevance of the research to the potential of promoting discussions about the teaching of this discipline, focusing on its formative aspects, aware of its presence in the most distinct areas of science.
\end{abstract}

Keywords: Mathematics Education. Phenomenology. Qualitative Research.

\section{Introdução}

Este artigo busca expor um estudo realizado com professores que ministram a disciplina de Cálculo Diferencial e Integral I (CDI-I) em cursos de engenharia na UNESP - Câmpus de Guaratinguetá. O objetivo foi conhecer modos de compreensão dos professores para com a disciplina na formação de engenheiros e, assim, contribuir com discussões sobre a formação docente para ensinar matemática nas engenharias, a partir do que é dito pelos sujeitos que atuam na formação de engenheiros. 
A pesquisa foi motivada pelos altos índices de retenção de alunos em tal unidade curricular, nos cursos de engenharia na UNESP-Câmpus de Guaratinguetá, mas encontrou permitiu lançarmo-nos a entender essa problemática recorrendo a experiências em outras instituições formadoras, relatadas em pesquisas. Nesse caminhar, nos encontramos com Nasser (2015), Rezende (2003) e Cabral e Baldino (2006), que atestam a dificuldade do aspirante a engenheiro em CDI I, presente no início da graduação, como um problema comum e recorrente nas mais diversas instituições formadoras e como uma especificidade que abrange as engenharias.

Com os esclarecimentos da complexidade do tema, nos perguntávamos: que compreensões o professor tem sobre o ensino de CDI I nos cursos de engenharia? Essa interrogação se mostrou com força para conduzir uma investigação, haja vista que transformações educacionais solicitam ser sustentadas pelo que vem da prática docente. Assim, nos lançamos em uma ampla pesquisa, que visa perseguir a interrogação “o que é isto, o Cálculo Diferencial e Integral na formação do engenheiro?”, da qual este trabalho se ocupa em desvelar compreensões dos professores de CDI-I.

A disciplina de CDI-I é anual e obrigatória para todos os cursos de engenharia da Faculdade e ocorre no primeiro ano do curso, possui uma carga horária de 180 horas e é estruturada pelos seguintes tópicos, de acordo com a ementa e o plano de ensino de CDI dos cursos²: uma revisão inicial englobando conteúdos de pré-cálculo (equações, módulo, inequações e as principais funções), limite e continuidade (noção intuitiva, propriedades, limites laterais, teorema do confronto, teorema do valor intermediário, limites infinitos e no infinito e assíntotas), introdução e aplicações de derivada (taxas de variação, reta tangente, função derivada, derivadas laterais e análise gráfica, máximos e mínimos relativos e absolutos, funções crescentes e decrescentes), regras de derivação (derivada de polinômios, derivada do produto e do quociente, derivada da Função composta: Regra da cadeia, construção da tabela básica de derivadas (exponenciais, logaritmos, trigonométricas, etc.), derivação implícita, derivada da função inversa, derivada de ordem superior, concavidade, pontos de inflexão, taxas relacionadas, linearização de funções, polinômios de Taylor e aproximações de funções, teorema de Rolle, teorema do valor médio para derivadas, problemas de otimização e regras de L’Hospital, formas indeterminadas, antiderivadas e propriedades.

No segundo semestre, normalmente estuda-se: integral (conceitos fundamentais, acréscimos e diferenciais, integral de Riemann: área sob o gráfico de uma função, teoremas, integrais indefinidas e técnicas de integração: integração por substituição, integração por partes, integrais de funções racionais, integração por substituição trigonométrica, aplicações da integral: área de regiões planas, volumes de sólidos, sólidos de revolução, volume por cascas cilíndricas, integrais impróprias, teste da comparação). Além disso, são estudadas funções reais de variáveis reais (conceitos básicos, gráficos, curvas de nível, limite e continuidade, derivadas parciais, diferenciabilidade, plano tangente, gradiente, derivada direcional, regra da cadeia, linearização, polinômios de Taylor em duas variáveis, máximos e mínimos relativos e absolutos, método dos multiplicadores de Lagrange). A disciplina de Cálculo I também abrange equações diferenciais ordinárias (conceitos básicos, campo de direções, equações diferenciais de primeira ordem, equações diferenciais

${ }^{1}$ Na UNESP - Câmpus de Guaratinguetá a disciplina de CDI-I é unificada, ou seja, todos os cursos seguem a mesma ementa 
lineares de segunda ordem: homogêneas e não homogêneas e aplicações: modelos populacionais, Lei do resfriamento, sistema massa-mola e circuitos).

As metodologias de ensino são diversificadas e de livre escolha de cada docente. Quanto aos critérios de aprovação, verifica-se a média anual do aluno (MA). Quando esta é maior ou igual a cinco, o estudante é considerado aprovado. A média anual é calculada pela seguinte fórmula: $\mathrm{MA}=\left(\mathrm{N}_{1}+\mathrm{N}_{2}+\mathrm{N}_{3}\right.$ $+\mathrm{N}_{4}$ )/4. Sendo que $\mathrm{N}_{1}, \mathrm{~N}_{2}, \mathrm{~N}_{3}$ e $\mathrm{N}_{4}$ são as notas bimestrais. É também de livre escolha do docente a composição das notas.

\title{
Percurso metodológico do caminho investigativo
}

A pesquisa aqui exposta, de cunho qualitativo, visa colocar em destaque a Matemática na engenharia, perguntando por significados do CDI para os professores desse curso, bem como pelo sentido que isso tem feito no cotidiano da universidade. Segundo Bicudo (2013) adjetivar uma pesquisa com o termo qualitativo quer dizer que se

engloba a ideia do subjetivo, passível de expor sensações e opiniões. O significado atribuído a essa concepção de pesquisa também engloba noções a respeito de percepções de diferenças e semelhanças de aspectos comparáveis de experiências, como por exemplo, da vermelhidão do vermelho, etc. (BICUDO, 2013, p. 116).

Para este trabalho, assumimos a postura fenomenológica.

\begin{abstract}
Fenomenologia é uma palavra composta pelos termos fenômeno mais logos. Fenômeno diz do que se mostra na intuição ou percepção e logos diz do articulado nos atos da consciência em cujo processo organizador a linguagem está presente, tanto como estrutura, quanto como possibilidade de comunicação e, em consequência, de retenção em produtos culturais postos à disposição no mundo vida. (BICUDO, 2011, p. 29).
\end{abstract}

Assumir uma postura fenomenológica é permitir que o sentido de CDI-I se exponha, na linguagem dos professores. A intensão é a compreender o fenômeno investigado 'ensino-de-cálculo-nasengenharias’, sem partir de concepções prévias.

Porém, é preciso que o pesquisador possua certa familiaridade com o contexto no qual o fenômeno se situa. Essa familiaridade lhe dá uma orientação inicial que não é concebida por teorias explicativas e previamente definida, mas é originada da sua vivência, do contexto no qual o fenômeno se situa e que gera a interrogação que conduz a pesquisa (OLIVEIRA, 2015, p. 67).

O modo de proceder em uma investigação fenomenológica traz consigo o que antecipa em termos de possibilidades de acontecer e o que se realizou em acontecimentos pretéritos, retidos na lembrança e em suas expressões sociais, históricas e culturais (BICUDO, 2011, p. 13).

Nesse sentido, procuramos avançar na investigação sobre como o CDI se mostra para os professores dos cursos de engenharia da UNESP - Câmpus de Guaratinguetá, seguindo o caminho anunciado por: 1) Estudo interpretativo de textos relevantes ao tema, buscando os significados de ciência, tecnologia e produção, articulando o discurso científico-tecnológico, filosófico e educacional; 2) Revisão da literatura, com a intenção de conhecer "o que" e "como" os pesquisadores estão abordando o tema; 3) 
Entrevista com professores de CDI-I, dos cursos de engenharia da UNESP - Câmpus de Guaratinguetá, sujeitos que vivenciam as complexidades do ensino e da aprendizagem dos conteúdos desta disciplina, com o intuito de compreender como entendem o CDI-I, no horizonte da formação de engenheiros.

Assim, fomos em busca destes professores, explicitando o objetivo da investigação e convidandoos a contribuir com o debate educacional. No ano de 2017 havia, no Câmpus de Guaratinguetá, 10 professores de Cálculo Diferencial e Integral concursados e contratados. Quanto à titulação, 2 eram doutorandos, 5 eram doutores e 3 livre-docentes. Destacamos, também, a formação acadêmica e o tempo de experiência de cada professor na disciplina focada nesse estudo. Tais dados estão expostos no Quadro I.

Quadro I - Formação acadêmica de cada professor e tempo que ministra a disciplina na instituição

\begin{tabular}{|c|c|c|c|c|}
\hline Professor & Graduação & Mestrado em: & Doutorado em: & $\begin{array}{r}\text { Tempo de } \\
\text { experiência }\end{array}$ \\
\hline P1 & $\begin{array}{l}\text { Matemática } \\
\text { (Licenciatura) }\end{array}$ & $\begin{array}{l}\text { Educação } \\
\text { Matemática }\end{array}$ & Educação Matemática & 6 anos \\
\hline P2 & $\begin{array}{l}\text { Matemática } \\
\text { (Licenciatura) }\end{array}$ & $\begin{array}{l}\text { Educação } \\
\text { Matemática }\end{array}$ & $\begin{array}{l}\text { Ensino de Ciências e } \\
\text { Matemática }\end{array}$ & 3 anos \\
\hline P3 & $\begin{array}{l}\text { Matemática } \\
\text { (Licenciatura) }\end{array}$ & Meteorologia & Psicologia Social & 37 anos \\
\hline $\mathrm{P} 4$ & $\begin{array}{l}\text { Matemática } \\
\text { (Licenciatura) }\end{array}$ & $\begin{array}{l}\text { Engenharia e } \\
\text { Tecnologia } \\
\text { Espacial }\end{array}$ & $\begin{array}{l}\text { Engenharia e Tecnologia } \\
\text { Espacial }\end{array}$ & 7 anos \\
\hline P5 & $\begin{array}{l}\text { Física } \\
\text { (Bacharelado) }\end{array}$ & Astronomia & Astronomia & 10 anos \\
\hline P6 & $\begin{array}{l}\text { Física } \\
\text { (Bacharelado) }\end{array}$ & $\begin{array}{l}\text { Ciências } \\
\text { Espaciais }\end{array}$ & $\begin{array}{l}\text { Engenharia e Tecnologia } \\
\text { Espacial }\end{array}$ & 10 anos \\
\hline P7 & $\begin{array}{l}\text { Física } \\
\text { (Bacharelado) }\end{array}$ & Física & $\begin{array}{l}\text { Engenharia e Tecnologia } \\
\text { Espacial }\end{array}$ & 6 anos \\
\hline P8 & $\begin{array}{l}\text { Física } \\
\text { (Bacharelado) }\end{array}$ & Física & Física & 16 anos \\
\hline P9 & $\begin{array}{l}\text { Física } \\
\text { (Licenciatura e } \\
\text { Bacharelado) }\end{array}$ & Física & Física & 7 anos \\
\hline P10 & $\begin{array}{l}\text { Física } \\
\text { (Licenciatura) }\end{array}$ & $\begin{array}{l}\text { Engenharia } \\
\text { Aeronáutica e } \\
\text { Mecânica }\end{array}$ & Dinâmica Orbital & 21 anos \\
\hline
\end{tabular}

Fonte: Os autores

Todos os professores concursados foram convidados a conceder entrevista, aceitaram o convite e autorizaram o uso de suas falas, as quais nós, pesquisadores, garantimos o anonimato, tendo em vista que o interesse estava no dito por estes profissionais e não em quem disse.

$\mathrm{O}$ encontro com esses professores se deu individualmente. A eles foi perguntado "Como você percebe o Cálculo Diferencial e Integral I na formação do engenheiro?” e deixamos que falassem livremente sobre suas experiências. Gravamos o encontro e posteriormente transcrevemos, ou seja, textualizamos cada discurso da experiência vivida dos professores. Assim, após a transcrição, os discursos

passam a ser tomados, pelo pesquisador, como textos que expressam compreensões articuladas da experiência vivida, numa linguagem que se abre à interpretação. $O$ pesquisador está envolto na sistematicidade do modo de proceder a pesquisa, realizando 
os passos iniciais da análise fenomenológica que envolve dois grandes momentos: a análise ideográfica e a análise nomotética (PAULO; AMARAL; SANTIAGO, 2010, p. 74).

O estudo dos textos descritivos da experiência expressada pelos professores nos permitiu análises e reflexões encaminhadas, segundo a metodologia de pesquisa adotada, em dois momentos distintos: a Análise Ideográfica e a Análise Nomotética.

A análise ideográfica se refere ao "emprego de ideogramas, ou seja, de expressões de ideias por meio de símbolos [...] a raiz do termo está em ideografia que diz da representação de ideias por meio de símbolos gráficos” (BICUDO, 2011, p. 58).

$\mathrm{Na}$ análise ideográfica, o pesquisador se volta para aspectos pontuais e singulares que se destacam ao atentar para o estudo de campo. Buscam-se pelos aspectos importantes que emergem da vivência do fenômeno e que se constituem em polos de análise, cujo sentido se mostra significativo diante da complexidade da situação vivida. A interrogação orienta as articulações produzidas pelo pesquisador (SANTOS, 2013. p. 49-50).

Já na análise nomotética, o pesquisador busca por generalizações a partir dos aspectos individuais. "Essas convergências dos aspectos individuais, percebidas nos discursos dos sujeitos, levam o pesquisador às Categorias Abertas, grandes regiões de generalidades que passam a ser interpretadas pelo pesquisador" (PAULO; AMARAL; SANTIAGO, 2010, p. 74), e que revelam o fenômeno investigado.

$\mathrm{Na}$ análise ideográfica, destacamos das entrevistas as ideias compreendidas a partir da fala dos professores sobre o CDI-I, à luz da pergunta norteadora do trabalho. Tais ideias, recortes de suas falas, foram interpretadas, reescritas em unidades significativas (US) e expostas em ideias nucleares, assim denominadas por serem asserções mais abrangentes, que estruturam o sentido do dito pelos sujeitos. Em nossa investigação, os dados foram produzidos junto com os professores ao explicitarmos o objetivo da investigação, perguntando a eles sobre suas compreensões a respeito do ensino de CDI nos cursos de engenharia. "Esses discursos, ao serem descritos, passam a ser tomados, pelo pesquisador, como texto que expressam compreensões articuladas da experiência vivida, numa linguagem que se abre à interpretação" (PAULO; AMARAL; SANTIAGO, 2010, p. 74).

O movimento de análise, exposto no Quadro II (em anexos), é composto por cinco colunas. $\mathrm{Na}$ primeira, identificamos o sujeito da pesquisa com $\mathrm{S}$ de sujeito, seguido de um número que representa uma ordem por nós dada aos 10 professores, identificando o recorte de sua fala pela letra U (de unidade significativa) e novamente um número para dizer da ordem de U de cada sujeito.

Assim, a identificação S1U1 refere-se ao sujeito 1 e a primeira unidade destacada na fala desse sujeito.

\section{Revelando os dados e perguntado pelo que eles nos dizem}

$\mathrm{Na}$ análise ideográfica, identificamos que os professores, ao falarem sobre suas compreensões a respeito de "o que é isto, o Cálculo Diferencial e Integral no curso de engenharia?", destacam a importância dessa disciplina para a formação do engenheiro, considerando-a como 
base/conhecimento/ferramenta/fundamento para o curso. Finalizada a análise ideográfica, iniciamos o movimento de análise nomotética, cujo objetivo é esclarecer o significado das convergências identificadas na análise ideográfica.

Ao analisar o dito pelos professores, percebemos que algumas ideias trazidas nas falas dos sujeitos expressavam pontos de vista semelhantes. Ao questionar o sentido do dito pelos sujeitos sobre CDI-I, entendemos haver outras convergências possíveis. Para expor esse movimento de análise, construímos o Quadro III (ver anexos).

Ao finalizar o movimento de análise nomotética, concluímos que os professores compreendem o Cálculo Diferencial e Integral da seguinte maneira:

- Como uma ferramenta matemática para modelar e compreender determinados fenômenos, que são objetos de estudo da engenharia;

- Como base onde se estrutura o conhecimento do engenheiro;

- Como um conhecimento necessário para a formação do engenheiro.

Essas são as categorias abertas que caracterizam o fenômeno investigado, e são assim denominadas por não serem dadas a priori, mas sim, constituídas com o desenvolvimento da pesquisa. Tais categorias possibilitam a compreensão sobre o fenômeno investigado. Em outras palavras, significa dizer que o Cálculo Diferencial e Integral é um conhecimento/base/ferramenta necessário para os cursos de engenharia.

Usaremos essas três palavras agrupadas (conhecimento/base/ferramenta), pois consideramos que na fala dos sujeitos entrevistados, a palavra conhecimento é dita como sinônimo de um saber, nesse caso matemático, necessário para a formação do engenheiro. Base é trazida como sinônimo de algo necessário para estruturar a formação do engenheiro, ou seja, é o Cálculo Diferencial e Integral que estrutura a formação desse profissional, em outras palavras, é o conhecimento necessário para a formação específica. Já a palavra ferramenta é dita como sinônimo de um conhecimento necessário (uma base), para a formação do estudante de engenharia.

Porém, nos questionamos: o que significa afirmar que o Cálculo Diferencial e Integral é um conhecimento/base/ferramenta para o curso de engenharia, encontramos poucos textos que tangenciam a temática em discussões envolvendo o ensino e a aprendizagem desta disciplina em diferentes cursos de Ensino Superior.

Murta e Máximo (2004), por exemplo, compreendem o Cálculo Diferencial e Integral como uma "ferramenta poderosa de trabalho para a Engenharia", cujas aplicações fundamentam o estudo e a modelagem de problemas reais das áreas de atuação do engenheiro moderno.

O caráter básico do Cálculo é, portanto, o de ampla aplicabilidade, o que teoricamente possibilita aos professores que ministram cursos na área atuarem de forma eficaz na qualificação de um profissional crítico e preparado para o enfrentamento dos desafios que se colocam atualmente no campo da Engenharia moderna (MURTA; MÁXIMO, 2014, p. 4). 
Há um consenso de que o Cálculo Diferencial e Integral é um conhecimento de grande aplicabilidade em diversas ciências e, dessas, destacam-se as engenharias, que estudam fenômenos como movimentos, crescimentos e decaimentos, taxas relacionadas, entre outros (FERRUZI, 2003, p. 30).

Nesse sentido, entende-se o Cálculo Diferencial e Integral como base para a compreensão de outros saberes e para a produção de novos conhecimentos nas diferentes áreas das Ciências Exatas. No entanto, há discordância sobre o modo de apresentação do cálculo enquanto disciplina. Muitos são os profissionais que "acreditam que o curso de cálculo deve enfatizar as aplicações, desenvolvendo habilidades técnicas. Porém, há outros profissionais que consideram que a única forma de realmente compreender o cálculo é começar com um tratamento matemático dos números reais” (BARUFI, 1999, p.66). Essa dicotomia sobre o tratamento que deve ser dado ao Cálculo Diferencial e Integral nos cursos superiores está intrinsecamente ligada à natureza do Cálculo, que é "uma Ciência dedutiva e um ramo da matemática pura. Ao mesmo tempo, possui fortes raízes em problemas físicos. E que muito de sua potência e beleza deriva da variedade de suas aplicações" (BARUFI, 1999, p. 66).

Independentemente das escolhas feitas pelo professor, é preciso clareza das escolhas, haja vista que o modo como é feita a abordagem dos conceitos interfere nos sentidos e significados constituídos pelos alunos.

\section{Considerações finais}

O relatado pela literatura mostra que a disciplina de Cálculo Diferencial e Integral, muitas vezes, enfatiza a técnica e não abre espaço para reflexões sobre o aprendido, "provocando assim, a falta de conhecimento sobre as aplicações da Matemática no curso, bem como uma visão ingênua do papel da Matemática na sociedade" (FERRUZI, 2003, p. 2). O resultado dessa prática educativa, segundo a mesma autora, é o agravante cenário das dificuldades em Matemática que rompem as barreiras da Educação Básica e se manifestam no Ensino Superior, destacando-se, nesse cenário, os cursos de engenharia.

O ensino de Cálculo Diferencial e Integral carece de atenção de todas as instituições que formam profissionais da área de exatas, visto que é um conhecimento necessário à formação de profissionais dessa área e que atualmente é uma disciplina com altos índices de reprovação e evasão, conforme constatam diversos autores que se dedicam ao assunto, tais como: Barufi (1999), Diogo (2000), Mocrosky e Alves (2011), entre outros.

Promover discussões acerca do ensino dessa disciplina, focando nos seus aspectos formativos aplicados a diversas profissões, é algo que se faz necessário, visto que os profissionais que trabalham com essa disciplina são de distintas formações e dão à disciplina abordagens metodológicas e didáticas diferentes.

Quanto à resposta para a questão norteadora da pesquisa, "o que é isto o Cálculo Diferencial e Integral na formação do engenheiro?", abordada nesse texto a partir do que os professores de Cálculo Diferencial e Integral percebem dessa disciplina na formação desses profissionais, podemos dizer que o cálculo é o conhecimento/base/ferramenta para a formação desses profissionais. 
Porém, consideramos que é necessário tematizar o sentido de conhecimento/base/ferramenta assumido no cotidiano universitário, com a intenção de esclarecer as concepções que sustentam o ensino dessa disciplina, bem como contribuir com a prática desses professores.

\section{Referências}

BARUFI, M. C. B. A construção/negociação de significados no curso universitário inicial de Cálculo Diferencial e Integral. 1999. 195 f. Tese (Doutorado em Educação) - Faculdade de Educação da USP. Universidade de São Paulo, São Paulo, 1999.

BICUDO, M. A. V. Pesquisa qualitativa e pesquisa qualitativa segundo a abordagem fenomenológica. In: BORBA, M. C.; ARAÚJO, J. L. (Orgs.). Pesquisa Qualitativa em Educação Matemática. 5. ed. Belo Horizonte: Autêntica Editora, 2013. p.116.

BICUDO, M. A. V. (Org.). Pesquisa Qualitativa Segundo a Visão Fenomenológica. 1 ed. São Paulo: Cortês, 2011.

DIOGO, M. das G. V. S. Uma alternativa para o ensino de Cálculo de funções de uma variável real. 2000.

Dissertação (Mestrado). Universidade Federal de Santa Catarina - UFSC, Florianópolis, 2000.

FERRUZZI, E. C. A modelagem Matemática como estratégia de ensino e aprendiragem do cálculo diferencial e integral nos cursos superiores de tecnologia. 2003. 154 p. Dissertação (Mestrado em Engenharia de Produção e Sistemas). Universidade Federal de Santa Catarina - UFSC, Florianópolis, 2003.

MOCROSKY, L. F.; ALVES, A. C. Um Estudo sobre o Cálculo Diferencial e Integral na Formação de Engenheiros. In: CONGRESSO BRASILEIRO DE EDUCAÇÃO EM ENGENHARIA, n. 39, 2011, Blumenau - SC. Anais... Blumenau - SC: ABENGE, 2011. p. 30-31.

MURTA, J. L. B.; MÁXIMO, G. C. Cálculo Diferencial e Integral nos cursos de Engenharia da UFOP: Estratégias e desafios no ensino aprendizagem. In: COBENGE. 2004. Ouro Preto - MG. Anais... Ouro Preto - MG, 2004, p. 1-11. Disponível em:

http://www.abenge.org.br/cobenge/arquivos/15/artigos/02_070.pdf. Acesso em: nov. 2019.

PAULO, R. M.; AMARAL, C. L. C.; SANTIAGO, R. A. A pesquisa fenomenológica: explicitando uma possibilidade de compreensão do ser-professor de Matemática. Revista Brasileira de Pesquisa em Educação em Ciências, v. 10, n. 3, p. 71-85, 2010. Disponível em:

https://seer.ufmg.br/index.php/rbpec/article/view/2290/1689. Acesso em: nov. 2019.

REZENDE, W. M. O Ensino de Cálculo: Dificuldades de Natureza Epistemológica. Tese (Doutorado). Faculdade de Educação da USP. Universidade de São Paulo, São Paulo, 2003. 
Anexos

Quadro II - Análise ideográfica dos dados

\begin{tabular}{|c|c|c|c|c|}
\hline \multicolumn{5}{|c|}{ Como você percebe o Cálculo Diferencial e Integral I na formação do engenheiro? } \\
\hline US & Fala do sujeito & Interpretação & $\begin{array}{l}\text { Unidade } \\
\text { Significativa }\end{array}$ & Ideias Nucleares \\
\hline S1U1 & $\begin{array}{l}\text { Ainda não consegui } \\
\text { formar uma opinião } \\
\text { sobre isso, até que } \\
\text { ponto eles } \\
\text { realmente vão } \\
\text { utilizar na prática } \\
\text { tudo o que é } \\
\text { ensinado em cálculo } \\
\text { I [...]. }\end{array}$ & $\begin{array}{l}\text { Opinião: Posição precisa, } \\
\text { ponto de vista adotado; ideia, } \\
\text { teoria, tese. } \\
\text { Utilizar: Lançar mão de fazer } \\
\text { uso de; usar, empregar, aplicar. }\end{array}$ & $\begin{array}{l}\text { O professor não } \\
\text { tem uma opinião } \\
\text { relacionada à } \\
\text { formação do } \\
\text { engenheiro. }\end{array}$ & $\begin{array}{l}\text { O professor não } \\
\text { tem uma opinião } \\
\text { sobre o CDI e a } \\
\text { formação do } \\
\text { engenheiro. }\end{array}$ \\
\hline S2U1 & $\begin{array}{l}{[\ldots] \text { o foco no curso }} \\
\text { de engenharia é: } \\
\text { Para que serve? O } \\
\text { objetivo são as } \\
\text { aplicações, apesar de } \\
\text { ser importante a } \\
\text { gente sempre } \\
\text { demonstrar as } \\
\text { teorias e } \\
\text { propriedades, mas o } \\
\text { enfoque é as } \\
\text { aplicações [...]. }\end{array}$ & $\begin{array}{l}\text { Foco: } \text { Ponto para o qual } \\
\text { converge alguma coisa. } \\
\text { Demonstrar: Raciocínio que } \\
\text { torna evidente o caráter verídico } \\
\text { de uma proposição, ideia ou } \\
\text { teoria. } \\
\text { Aplicação: Execução, prática, } \\
\text { utilização. } \\
\text { "a. do princípio de Arquimedes" }\end{array}$ & $\begin{array}{l}\text { O curso de cálculo } \\
\text { na engenharia é } \\
\text { baseado em } \\
\text { aplicações. }\end{array}$ & $\begin{array}{l}\text { O cálculo auxilia } \\
\text { nas aplicações da } \\
\text { engenharia. }\end{array}$ \\
\hline S3U1 & $\begin{array}{l}\text { Para mim, a } \\
\text { disciplina de cálculo } \\
\text { ela proporciona um } \\
\text { ferramental, uma } \\
\text { base para todas as } \\
\text { disciplinas e para } \\
\text { todos os assuntos } \\
\text { que vão ser } \\
\text { abordados voltado } \\
\text { para a ciências } \\
\text { exatas [...]. }\end{array}$ & $\begin{array}{l}\text { Proporcionar: Dar a (alguém) a } \\
\text { oportunidade de (algo); } \\
\text { oferecer, promover, propiciar. }\end{array}$ & $\begin{array}{l}\text { Serve como } \\
\text { ferramenta para a } \\
\text { continuação da } \\
\text { formação do } \\
\text { engenheiro. }\end{array}$ & $\begin{array}{l}\text { O curso de } \\
\text { cálculo é uma } \\
\text { ferramenta } \\
\text { fundamental } \\
\text { para a } \\
\text { engenharia. }\end{array}$ \\
\hline S3U2 & $\begin{array}{l}{[\ldots . .] \text { não dá para }} \\
\text { pensar um } \\
\text { profissional da } \\
\text { engenharia sem } \\
\text { conhecimento de } \\
\text { cálculo }[. . .] .\end{array}$ & $\begin{array}{l}\text { Conhecimento: Domínio, } \\
\text { teórico ou prático, de uma arte, } \\
\text { uma ciência, uma técnica, etc. }\end{array}$ & $\begin{array}{l}\text { É imprescindível o } \\
\text { conhecimento de } \\
\text { cálculo para o } \\
\text { engenheiro. }\end{array}$ & $\begin{array}{l}\text { O curso de } \\
\text { cálculo é um } \\
\text { conhecimento } \\
\text { fundamental } \\
\text { para a } \\
\text { engenharia. }\end{array}$ \\
\hline S4U1 & $\begin{array}{l}\text { Eu acredito que o } \\
\text { cálculo é uma } \\
\text { disciplina base em } \\
\text { várias matérias, }\end{array}$ & $\begin{array}{l}\text { Disciplina: Ciência, ramo de } \\
\text { conhecimento; matéria escolar. } \\
\text { Base: O que serve de apoio, de } \\
\text { princípio ou fundamento. }\end{array}$ & $\begin{array}{l}\text { O cálculo serve } \\
\text { como base durante } \\
\text { o curso inteiro da } \\
\text { engenharia. }\end{array}$ & $\begin{array}{l}\text { O curso de } \\
\text { cálculo é base } \\
\text { para as } \\
\text { disciplinas de } \\
\text { engenharia. }\end{array}$ \\
\hline
\end{tabular}




\begin{tabular}{|c|c|c|c|c|}
\hline & $\begin{array}{l}\text { inclusive na } \\
\text { engenharia. }[\ldots]\end{array}$ & Princípio ou origem. & & \\
\hline S4U2 & $\begin{array}{l}{[\ldots] \text { acho que na }} \\
\text { formação do } \\
\text { engenheiro, a } \\
\text { disciplina de cálculo } \\
\text { é essencial e por } \\
\text { isso o tem que ser } \\
\text { olhado de uma } \\
\text { forma mais delicada. }\end{array}$ & $\begin{array}{l}\text { Essencial: Que constitui o } \\
\text { mais básico ou o mais } \\
\text { importante em algo; } \\
\text { fundamental. }\end{array}$ & $\begin{array}{l}\text { O curso de } \\
\text { cálculo, por ser } \\
\text { fundamental, tem } \\
\text { que ser tratado de } \\
\text { uma maneira mais } \\
\text { diferente. }\end{array}$ & $\begin{array}{l}\text { O curso de } \\
\text { cálculo é } \\
\text { essencial para a } \\
\text { formação do } \\
\text { engenheiro. }\end{array}$ \\
\hline S5U1 & $\begin{array}{l}\text { É fundamental, } \\
\text { principalmente } \\
\text { quando for aplicado } \\
\text { nas outras matérias } \\
\text { da engenharia, como } \\
\text { cálculo II [...]. }\end{array}$ & $\begin{array}{l}\text { Fundamental: Que tem caráter } \\
\text { essencial e determinante; básico, } \\
\text { indispensável. }\end{array}$ & $\begin{array}{l}\text { Fundamental para } \\
\text { a continuação em } \\
\text { Cálculo } \\
\text { Diferencial e } \\
\text { Integral II. }\end{array}$ & $\begin{array}{l}\text { O curso de } \\
\text { fundamental } \\
\text { para a formação } \\
\text { do engenheiro }\end{array}$ \\
\hline S5U2 & $\begin{array}{l}{[\ldots . .] \text { se você vai }} \\
\text { escrever um texto } \\
\text { você precisa de } \\
\text { gramática, conjugar } \\
\text { verbos, mas na } \\
\text { engenharia a } \\
\text { ferramenta que se } \\
\text { tem é a matemática } \\
\text { e isso se encontra } \\
\text { no cálculo [...]. }\end{array}$ & $\begin{array}{l}\text { Matemática: Ciência que } \\
\text { estuda, por método dedutivo, } \\
\text { objetos abstratos (números, } \\
\text { figuras, funções) e as relações } \\
\text { existentes entre eles. }\end{array}$ & $\begin{array}{l}\text { A matemática é } \\
\text { um conceito muito } \\
\text { utilizado na } \\
\text { engenharia e } \\
\text { grande parte é } \\
\text { obtido no curso de } \\
\text { cálculo. }\end{array}$ & $\begin{array}{l}\text { O cálculo auxilia } \\
\text { na compreensão } \\
\text { das aplicações da } \\
\text { engenharia. }\end{array}$ \\
\hline S6U1 & $\begin{array}{l}{[\ldots . .] \text { é muito }} \\
\text { importante, } \\
\text { qualquer } \\
\text { modelagem que ele } \\
\text { vai fazer com } \\
\text { relação aos } \\
\text { problemas, ele vai } \\
\text { precisar do cálculo } \\
{[\ldots . .]}\end{array}$ & $\begin{array}{l}\text { Modelagem: Área do } \\
\text { conhecimento que estuda a } \\
\text { simulação de sistemas reais a } \\
\text { fim de prever o seu } \\
\text { comportamento. }\end{array}$ & $\begin{array}{l}\text { Entende-se que o } \\
\text { cálculo tem sua } \\
\text { importância para o } \\
\text { desenvolvimento } \\
\text { de modelagens. }\end{array}$ & $\begin{array}{l}\text { O cálculo auxilia } \\
\text { na compreensão } \\
\text { das aplicações da } \\
\text { engenharia. }\end{array}$ \\
\hline S6U2 & $\begin{array}{l}{[\ldots . .] \text { ela é }} \\
\text { extremamente } \\
\text { importante para a } \\
\text { resolução de EDOs } \\
\text { e EDPs e o aluno } \\
\text { vai precisar de } \\
\text { embasamento do } \\
\text { cálculo }[. . .] .\end{array}$ & $\begin{array}{l}\text { Embasamento: Tudo aquilo } \\
\text { que pode ser utilizado para } \\
\text { fundamentar (alguma coisa); } \\
\text { fundamento. }\end{array}$ & $\begin{array}{l}\text { O engenheiro irá } \\
\text { precisar do cálculo } \\
\text { para resolver } \\
\text { equações } \\
\text { diferenciais. }\end{array}$ & $\begin{array}{l}\text { O cálculo auxilia } \\
\text { na compreensão } \\
\text { das aplicações da } \\
\text { engenharia. }\end{array}$ \\
\hline S7U1 & $\begin{array}{l}\text { É uma ferramenta } \\
\text { poderosa, talvez a } \\
\text { ferramenta mais } \\
\text { poderosa da } \\
\text { matemática, e na } \\
\text { engenharia deve }\end{array}$ & $\begin{array}{l}\text { Poderosa: Que tem muito } \\
\text { poder, grande influência. }\end{array}$ & $\begin{array}{l}\text { Compreende-se } \\
\text { que o cálculo tem } \\
\text { uma grande } \\
\text { importância na } \\
\text { matemática e isso } \\
\text { irá ajudar o }\end{array}$ & $\begin{array}{l}\text { O curso de } \\
\text { cálculo é uma } \\
\text { ferramenta } \\
\text { fundamental }\end{array}$ \\
\hline
\end{tabular}




\begin{tabular}{|c|c|c|c|c|}
\hline & $\begin{array}{l}\text { ajudar na resolução } \\
\text { de problemas [...]. }\end{array}$ & & $\begin{array}{l}\text { engenheiro a } \\
\text { resolver } \\
\text { problemas. }\end{array}$ & $\begin{array}{l}\text { para a } \\
\text { engenharia. }\end{array}$ \\
\hline S8U1 & $\begin{array}{l}{[\ldots . .] \text { ele dá os }} \\
\text { conceitos iniciais } \\
\text { necessários para } \\
\text { entender lógica, } \\
\text { toda a parte de } \\
\text { desenvolvimento } \\
\text { que ele vai aprender } \\
\text { na vida como } \\
\text { engenheiro }[. . .] .\end{array}$ & $\begin{array}{l}\text { Conceito: Imagem mental feita } \\
\text { de um objeto (concreto ou } \\
\text { abstrato) cujo conteúdo é de } \\
\text { extrema importância para o } \\
\text { pensamento; noção ou ideia } \\
\text { abstrata. } \\
\text { Lógica: Lógica moderna, } \\
\text { dedutiva, algorítmica ou } \\
\text { matemática, sistema científico } \\
\text { de raciocínio, que se divide em } \\
\text { cálculo das proposições e } \\
\text { cálculo funcional. }\end{array}$ & $\begin{array}{l}\text { Acredita-se que o } \\
\text { cálculo ajuda no } \\
\text { desenvolvimento } \\
\text { lógico do } \\
\text { engenheiro. }\end{array}$ & $\begin{array}{l}\text { O cálculo auxilia } \\
\text { nas aplicações da } \\
\text { engenharia. }\end{array}$ \\
\hline S8U2 & $\begin{array}{l}{[\ldots . .] \text { comparo com }} \\
\text { alguns cursos de } \\
\text { gestão, a maioria } \\
\text { dos nossos } \\
\text { engenheiros acabam } \\
\text { trabalhando com } \\
\text { gestão, e aí eu } \\
\text { pergunto para eles, } \\
\text { por que que ao } \\
\text { invés de } \\
\text { contratarem } \\
\text { gestores ou } \\
\text { administradores que } \\
\text { têm formação nisso, } \\
\text { contratam } \\
\text { engenheiros? } \\
\text { Porque vocês sabem } \\
\text { cálculo [...]. }\end{array}$ & $\begin{array}{l}\text { Gestão: Ação de gerir, de } \\
\text { administrar, de governar ou de } \\
\text { dirigir negócios públicos ou } \\
\text { particulares. }\end{array}$ & $\begin{array}{l}\text { O diferencial do } \\
\text { engenheiro } \\
\text { comparado com o } \\
\text { gestor é o curso de } \\
\text { cálculo. }\end{array}$ & $\begin{array}{l}\text { O cálculo é } \\
\text { importante para } \\
\text { a atuação } \\
\text { profissional do } \\
\text { engenheiro. }\end{array}$ \\
\hline S9U1 & $\begin{array}{l}{[\ldots . .] \text { primeiramente }} \\
\text { você está } \\
\text { apresentando uma } \\
\text { ferramenta } \\
\text { matemática que eles } \\
\text { vão usar ao longo da } \\
\text { formação toda } \\
\text { deles [...]. }\end{array}$ & $\begin{array}{l}\text { Formação: Ato ou efeito de } \\
\text { formar ou formar-se.1.Dar } \\
\text { corpo ou forma. 2.Organizar. }\end{array}$ & $\begin{array}{l}\text { O cálculo será } \\
\text { fundamental ao } \\
\text { longo da formação } \\
\text { do engenheiro. }\end{array}$ & $\begin{array}{l}\text { O curso de } \\
\text { cálculo é uma } \\
\text { ferramenta } \\
\text { fundamental } \\
\text { para o } \\
\text { engenheiro. }\end{array}$ \\
\hline S10 U1 & $\begin{array}{l}\text { Eu acho que é um } \\
\text { curso que dá um } \\
\text { ferramental básico } \\
\text { para os alunos da } \\
\text { engenharia [...]. }\end{array}$ & $\begin{array}{l}\text { Ferramental: Conjunto de } \\
\text { meios pelos quais se pode } \\
\text { realizar, perfazer ou alcançar } \\
\text { algo; instrumento. }\end{array}$ & $\begin{array}{l}\text { O cálculo serve } \\
\text { como ferramenta } \\
\text { para o engenheiro. }\end{array}$ & $\begin{array}{l}\text { O curso de } \\
\text { cálculo é uma } \\
\text { ferramenta } \\
\text { fundamental } \\
\text { para o } \\
\text { engenheiro. }\end{array}$ \\
\hline S10 U2 & $\begin{array}{l}\text { Eu vejo como uma } \\
\text { disciplina de apoio } \\
{[\ldots]}\end{array}$ & $\begin{array}{l}\text { Apoio: Auxílio; ajuda oferecida } \\
\text { a alguém. }\end{array}$ & $\begin{array}{l}\text { Entende-se que o } \\
\text { cálculo auxilia no }\end{array}$ & $\begin{array}{l}\text { O curso de } \\
\text { cálculo é base }\end{array}$ \\
\hline
\end{tabular}




\begin{tabular}{|l|l|l|l|l|}
\hline & & & $\begin{array}{l}\text { entendimento de } \\
\text { outras disciplinas. }\end{array}$ & $\begin{array}{l}\text { para a } \\
\text { engenharia. }\end{array}$ \\
\hline
\end{tabular}

Fonte: os autores

Quadro III - Convergências identificadas na fala dos professores

\begin{tabular}{|c|c|c|c|}
\hline \multicolumn{4}{|c|}{ Como você percebe o Cálculo Diferencial e Integral I na formação do engenheiro? } \\
\hline Ideias Nucleares & $\begin{array}{l}\text { Como uma } \\
\text { ferramenta para a } \\
\text { engenharia }\end{array}$ & $\begin{array}{c}\text { Como base para compreender } \\
\text { as aplicações }\end{array}$ & $\begin{array}{c}\text { Como conhecimento } \\
\text { necessário para a } \\
\text { formação do } \\
\text { engenheiro }\end{array}$ \\
\hline $\begin{array}{l}\text { O cálculo auxilia nas } \\
\text { aplicações da } \\
\text { engenharia. }\end{array}$ & $\mathrm{X}$ & $\mathrm{X}$ & \\
\hline $\begin{array}{l}\text { O curso de cálculo é } \\
\text { uma ferramenta } \\
\text { fundamental para a } \\
\text { engenharia. }\end{array}$ & $\mathrm{X}$ & & \\
\hline $\begin{array}{l}\text { O curso de cálculo é } \\
\text { um conhecimento } \\
\text { fundamental para a } \\
\text { engenharia. }\end{array}$ & & & $\mathrm{X}$ \\
\hline $\begin{array}{l}\text { O curso de cálculo é } \\
\text { base para as disciplinas } \\
\text { de Engenharia. }\end{array}$ & & $\mathrm{X}$ & \\
\hline $\begin{array}{l}\text { O curso de cálculo é } \\
\text { fundamental para a } \\
\text { formação do } \\
\text { engenheiro. }\end{array}$ & & & $\mathrm{X}$ \\
\hline $\begin{array}{l}\text { O cálculo auxilia na } \\
\text { compreensão das } \\
\text { aplicações da } \\
\text { engenharia. }\end{array}$ & $\mathrm{X}$ & $\mathrm{X}$ & \\
\hline $\begin{array}{l}\text { O cálculo é importante } \\
\text { para a atuação } \\
\text { profissional do } \\
\text { engenheiro. }\end{array}$ & & & $\mathrm{X}$ \\
\hline $\begin{array}{l}\text { O curso de cálculo é } \\
\text { base para a engenharia. }\end{array}$ & & $\mathrm{X}$ & \\
\hline
\end{tabular}

Fonte: Os autores 
C-ISSN: 2525-3514

Recebido em: 20 set. 2019 / Aprovado em: 22 nov. 2019

\section{Para referenciar este texto}

RIBEIRO JUNIOR, Milton Luís; MONDINI, Fabiane; MOCROSKY, Luciane Ferreira. O cálculo diferencial e integral e a formação de engenheiros. Cadernos de Pós-graduação, São Paulo, v. 18, n.2, p. 249261, jul./dez. 2019. Disponível em: https://doi.org/10.5585/cpg.v18n2.10365. 